\title{
2006-2167: PREPARING BIOMEDICAL ENGINEERS FOR CAREER ADVANCEMENT: THE HEALTHCARE TECHNOLOGIES MANAGEMENT PROGRAM
}

\section{Jay Goldberg, Marquette University}

Dr. Goldberg is the Director of the Healthcare Technologies Management Program, Associate Professor of Biomedical Engineering at Marquette University, and Associate Adjunct Professor of Biophysics at the Medical College of Wisconsin. He has fourteen years of medical device product development experience with DePuy, Baxter Healthcare, Surgitek (R\&D Group Leader), and Milestone Scientific (Director of Technology and Quality Assurance). Dr. Goldberg has consulted for several start-up medical device companies and law firms on new product development projects and product liability cases, respectively, and is a registered Professional Engineer in Illinois and Wisconsin. He is a co-creator of the BMES-idea national design competition and writes a quarterly column on senior design for IEEE-EMBS magazine.

Education: B.S. General Engineering, University of Illinois, Urbana, IL, 1979; M.S. Bioengineering, University of Michigan, Ann Arbor, MI, 1980; Master of Engineering Management, Northwestern University, 1986; Ph.D. Biomedical Engineering (Biomaterials), Northwestern University, 1998 


\section{Preparing Biomedical Engineers for Career Advancement: The Healthcare Technologies Management Program}

Engineers working in industry often find that after several promotions, they reach a point where further advancement places them into a management position. These positions require more than technical, interpersonal, and communication skills. Managers must be able to get things done through other people and provide their subordinates with the tools, resources, and support to be successful. Making the transition from engineer to manager involves less doing and more delegating, and requires motivation, training, coaching, and evaluation skills. Managers need to understand how their functional areas and those of others in the organization help the company meet its goals. Knowledge of basic business functions such as accounting, marketing, finance, and an understanding of organizational behavior are also important.

Undergraduate biomedical engineering curricula include courses in math, physics, chemistry, biology, physiology, design, and the engineering sciences. Students usually take elective courses in the social studies and the humanities. Due to the lack of additional elective credits in an already full curriculum, very few biomedical engineers take any business or management courses as undergraduates, and few have an understanding of the regulatory aspects of medical device development.

Most engineers are not prepared for their first management position. They typically lack the management skills and business knowledge needed for the job. This contributes to the high rate of managerial failure among engineers. ${ }^{1}$ Recognizing the value of additional education in reducing the incidence of managerial failure, many engineers are preparing for career advancement by enrolling in part-time graduate management programs. These programs allow students to supplement their technical education with formal coursework in business and management while they continue to work full-time.

Medical device companies need engineers with technical and business skills, and an understanding of the economic and regulatory aspects of healthcare delivery. They need to invest in employee training and education to develop, promote, and retain key employees. For this reason, many employers will pay for continuing education programs through tuition reimbursement benefits.

There are a variety of part-time graduate management programs available to biomedical engineers. The Master of Business Administration (MBA) degree is typically a generic management degree that emphasizes the core business areas of marketing, finance, accounting, organizational behavior, and others. Programs in Engineering Management focus on technical management. They include core business courses with emphasis on technical areas such as production and control systems, quality control, operations research, research and development, and project management.

Biomedical engineers working in clinical or industrial environments have some unique educational needs that are not addressed by most undergraduate or graduate biomedical engineering programs, or graduate management programs. The Healthcare Technologies 
Management Program is designed to meet these needs. It combines business, technology, and healthcare and is ideal for biomedical engineers whose career goals include technical management for a medical device company or healthcare facility.

\section{Description of Program}

The Healthcare Technologies Management Program (HTM) has been described previously. ${ }^{2}$ It is jointly offered by Marquette University and the Medical College of Wisconsin in Milwaukee, Wisconsin. Graduates of the program earn a Master of Science degree in Healthcare Technologies Management from both institutions.

The objectives of the program are to provide engineers with a formal business and management education, update their technical skills, develop and understanding of the healthcare delivery and regulatory environments, and prepare students for placement and advancement into clinical, industrial, and consulting positions. The program is designed to train engineers to manage the design, development, commercialization, and regulatory compliance of medical devices, and the implementation, utilization, and assessment of hospital based healthcare technologies. It meets the unique needs of biomedical engineers by providing training in areas not covered in typical graduate business or technical degree programs.

The program consists of 15 courses representing 37.5 credit hours. Courses are offered in the evenings to accommodate working engineers and are taught at both institutions. Students may enroll as full or part-time students. Full-time students can complete the program in three semesters.

\section{$\underline{\text { Curriculum }}$}

The program includes courses in Healthcare Technologies Management and Business and Management. One technical and one professional development elective are also required. The Healthcare Technologies Management core curriculum includes the following courses:

- Survey of Biomedical Engineering Technology

Review of technologies employed in medicine for diagnosis, treatment, and prevention of chronic and acute diseases, as well as hospital support. The goal of the course is to familiarize students with the operating principles, economic aspects, and purposes of healthcare technologies in clinical care.

- Environment of Healthcare Delivery - (taught on-line)

Review of current models for healthcare delivery such as fee for service, managed care, capitated care, IPO's, and HMO's, and the existence of various models in different geographic regions and in response to economic incentives.

- Biomedical Technology Assessment

Introduction to healthcare technology assessment methods for hospital systems and medical businesses encompassing technical, clinical and business elements. Topics include clinical results analysis, gold standard comparison, Bland-Altman analysis, sensitivity/specificity analysis and business tradeoff analysis. Case studies of present and developing medical technologies are extensively used as examples of applied assessment methodologies. 
- Biomedical Technology Standards and Regulations

Overview of standards and regulations that impact the development, acquisition, and management of health care technologies. Discusses international technical standards, consensus technical standards, and FDA regulations regarding the manufacture, distribution, and use of medical devices. Examines how standards and regulations affect medical technologies at all stages of maturation, from prototype development, through testing, marketing, customer use, and into obsolescence. Examines how these standards and regulations affect technology viewed from different perspectives based on what a technology is (e.g. physical device or drug, information, and knowledge) and what technology causes in the adopting organizations (e.g. change, new processes).

- Ethics of Technology Utilization - (taught on-line)

Ethics applied to the utilization and management of healthcare technologies in a patient care setting. Topics include beneficence, nonmaleficence, quality-cost, resource allocation and personal-public conflicts, technology diffusion models and controls, clinical research and research integrity, and patient rights and confidentiality.

- Product Development of Medical Devices

Activities required for the design, development, and commercialization of new medical devices. Design, testing, regulatory, and legal requirements are presented along with project evaluation and management methods. Issues involving management of the product development process are discussed.

- Special Topics Seminar

Fall Semester: Communication Skills for Technical Managers Spring Semester: Making the Transition from Engineer to Manager

- Independent Study/Internship

Project or internship experience designed by the student to meet their career goals. Students will have faculty and industry or hospital advisors whom they will work with to design and complete their projects. Oral and written presentations are required of each student to obtain initial approval of their projects and present final results.

The Business/Management core curriculum includes the following courses:

- Accounting Foundations

- Managerial Accounting

- Marketing Management

- Financial Management

- Organizational Behavior

These courses are taught as part of the Executive MBA program at Marquette University.

Advantages of the Program

The Healthcare Technologies Management Program is the first graduate program in the United States to combine business, technology, and healthcare. It offers a practical, relevant curriculum designed to meet the unique needs of entry-level engineers and healthcare technology managers. It requires less time to complete than a master of business administration (MBA) degree, and is flexible to accommodate the career goals of the students. 
For engineers who plan on moving into and/or remaining in technical management, it is anticipated that the program will better address their needs than other educational programs. It provides training not covered in graduate business (MBA) or engineering (MS) programs in areas typically learned on the job. It also allows students to update their technical skills.

The HTM program is expected to qualify engineers for increasing management responsibilities and career advancement. Employers will benefit from the HTM program by developing skills in current employees, which should aid in retention of good employees. By taking courses in business and management, engineers will view their organizations with a more global perspective, which will help them understand the objectives of other departments within the organization. This should result in more effective interactions with marketing, finance, and other departments represented on their project teams. Graduates of the HTM program will be well equipped to help their employers meet their goals.

\section{Program Update}

At the end of the sixth year of the program in August 2005, 24 students were enrolled. The program produced 39 graduates. Details regarding these 63 students are listed below.

Full-time students: $\quad 28$

Part-time students: 35

Employers of part-time students:

Abbott Laboratories

GE Healthcare

Baxter Healthcare

Camtronics Medical Systems

Pharmacia

Advocate Health Systems

Graduates of program:

Pierce Milwaukee, Inc.

Blood Center of Southeastern Wisconsin

Medical College of Wisconsin

Circon-ACMI

Quest Diagnostics.

Graduate employment:

Industry:

(GE Healthcare, Siemens Medical Solutions, Phillips Medical Systems, Kimberly-Clark

Corp., Bioform, Inc., Smiths Medical PM, Inc., Cerner Corp., Johnson \& Johnson, Quest

Diagnostics, Pierce Milwaukee, LLC, Epic Systems Corp., )

Hospitals (clinical engineering): 6

(ARAMARK Healthcare Management Services, United States Air Force, VA Sierra

Nevada Healthcare System, US Department of Veteran's Affairs Medical Center, University of Maryland Medical Center)

Healthcare consulting firms: 5

(ECRI, Value Analysis and Systems Technologies, Marketics, Covance Laboratories, Inc.)

Academia: $\quad 1$

(Universidad Don Bosco, El Salvador)

Graduate School:

(University of Wisconsin - Madison, Ph.D. Industrial Engineering - Healthcare Delivery Systems) 
Graduates in Management Positions:

14

Examples of job titles of HTM graduates:

Associate Director

Director of Technology Assessment

Chief of Biomedical Engineering

Worldwide Product Director

Product Sales Manager

District Sales Manager

Field Marketing Manager

Business Analysis Manager

Product Service Manager

New Product Introductions Leader

Summary

The Healthcare Technologies Management Program offered by Marquette University and the Medical College of Wisconsin is a unique, innovative program designed to meet the needs of biomedical engineers and their employers. It provides several advantages over graduate business and technical degrees.

Feedback from graduates indicates that new engineering graduates entering the workforce after earning the MS in HTM were well prepared for positions in hospitals, medical device companies, and consulting firms. Experienced engineers stated that the degree prepared them well for advancement into management positions. Employers feel that the degree provides students with the skills, knowledge, and perspectives they look for when hiring and promoting engineers into technical management positions.

\section{$\underline{\text { References }}$}

1. Badawy, M. K. Developing Managerial Skills in Engineers and Scientists: Succeeding as a Technical Manager, Second Edition, Van Nostrand Reinhold, New York.

2. Goldberg, J. R. The Healthcare Technologies Management Program, IEEE Engineering in Medicine and Biology Magazine, pgs. 49-52, January/February 2003. 